\title{
The role of volcanism in global-scale climate cooling at the Eocene- Oligocene transition.
}

\author{
CHARLOTTE E. GREEN ${ }^{1}$, ALEX DICKSON ${ }^{1}$, TAMSIN A. \\ MATHER $^{2}$, STEPHEN T. GRIMES ${ }^{3}$ AND SANDER H.J.M. \\ VAN DEN BOORN ${ }^{4}$ \\ ${ }^{1}$ Royal Holloway, University of London \\ ${ }^{2}$ University of Oxford \\ ${ }^{3}$ University of Plymouth \\ ${ }^{4}$ Shell Global Solutions International B.V \\ Presenting Author: charlotte.green.2019@live.rhul.ac.uk
}

From $\sim 50$ Ma the Paleogene greenhouse climate began to deteriorate into the early Oligocene ( $\sim 34 \mathrm{Ma})$, culminating with abrupt global cooling and the formation of partial/ephemeral Antarctic ice sheets at the Eocene-Oligocene boundary - a climate event known as the Eocene-Oligocene transition (EOT). Most studies attribute the EOT to either i) tectonically-driven ocean circulation changes or ii) a gradual decline in $\mathrm{CO}_{2}$. Volcanism was previously disregarded as an EOT cooling mechanism, but recent research on large igneous provinces (LIPs) demonstrates their potential climate forcing ability. Large igneous provinces may generate cooling through carbon cycle perturbation, by rapid weathering of juvenile volcanic products and/or inciting changes in marine productivity - both of which intensify $\mathrm{CO}_{2}$ drawdown. Additionally, injection of sulfur dioxide into the atmosphere and the formation of sulfate aerosol impacts the Earth's radiative budget and indirectly affects atmospheric circulation, which reduces surface temperatures over shorter timescales.

The Afro-Arabian LIP was active around the EOT, with its main phase of volcanism occurring $\sim 31-29$ Ma. However, a pre$31 \mathrm{Ma}$ flood basalt ( $\sim 34 \mathrm{Ma}$ ) discovered in the Lake Tana region warrants renewed investigation of the potential link between Afro-Arabian LIP volcanism and the EOT global cooling event. We present mercury $(\mathrm{Hg})$ data and mercury/total organic carbon (Hg/TOC) ratios from the Para-Tethys Sea and eastern Atlantic Ocean to examine global $\mathrm{Hg}$-cycle perturbations around the EOT. Mercury is a trace component of volcanic gas emitted from modern volcanoes and can be globally distributed and deposited into the oceans, therefore, we use sedimentary $\mathrm{Hg} / \mathrm{TOC}$ ratios as a geochemical tracer of volcanism. In combination with other analyses, some volcanic, sedimentary and environmental influences on $\mathrm{Hg}$ are also considered to better attribute $\mathrm{Hg}$ anomalies to LIP volcanism. Our data allow a direct test of the volcanism-climate connection during the EOT. 